\title{
Service and its association with matching into a primary care residency
}

This article was published in the following Dove Press journal:

Advances in Medical Education and Practice

10 March 2015

Number of times this article has been viewed

\section{Ansab Khwaja \\ Douglas C Schaad \\ Richard W Arnold}

University of Washington School of Medicine, Seattle, WA, USA
Correspondence: Ansab Khwaja General Internal Medicine Center, Box 345760, 4245 Roosevelt Way NE, Seattle, WA 98105 , USA

Email ansab@uw.edu
Background and objectives: There is a shortfall in the primary care workforce, and an effort is needed in learning more about what motivates students to work as generalists. There is enthusiasm about service as a potential motivator. The objective is to determine whether there is an association between high participation in service and selection of a primary care residency.

Methods: This is a retrospective cohort analysis. The service award was used to delineate two groups, recipients and non-recipients, with the recipients considered high service participators. This was associated with residency match data using test of proportions to examine relationships between service and selection of a primary care residency and other secondary factors.

Results: Of award recipients, $57.3 \%$ matched in primary care, compared to $52.8 \%$, though this did not reach statistical significance. Service was linked with induction into Alpha Omega Alpha honor society $(23.3 \%$ versus $14.6 \%)$ and induction into the Gold Humanism Honor Society (22.6\% versus $10.4 \%)$, with statistical significance.

Conclusion: This was an unsuccessful attempt to find a link between service and a primary care career choice, though there is a trend in the direction. The association with induction into the humanism honor society suggests that service is linked with development and/or retention of positively viewed qualities in medical students.

Keywords: primary care, community service, medical education

\section{Introduction}

The United States is currently facing a serious shortfall in the primary care workforce with multiple factors contributing. Physicians are retiring while the population is aging, ${ }^{1}$ with current estimates projecting increasing office visits with the need of nearly 52,000 additional primary care physicians by $2025 .^{2}$ Primary care remains important in mortality reduction and policy makers urge increase in the number of generalists. ${ }^{3-5}$ Medical schools are therefore tasked with producing a new generation of primary care physicians to meet current and future demands. Medical schools provide undergraduate medical education that prepares the student to successfully enter graduate medical education, in a program called a Residency. For residency matching, students apply and interview for different programs. Applicants and programs rank each other at the completion of this time period and the non-profit organization known as the National Resident Matching Program matches students into programs.

This study aims to look at the relationship between service by medical students at the University of Washington School of Medicine (UWSOM) and selection of a primary care residency. As the UWSOM serves a large geographical area known as the WWAMI (Washington, Wyoming, Alaska, Montana, Idaho region) and one goal 
is to serve the needs of this area, there is also an evaluation for a correlation between service in the region during medical school and matching into a program in the region. We consider service to be an un-compensated activity performed to benefit or strengthen communities, individuals or organizations in need. An example is a student volunteering at a free clinic for patients without medical insurance. Another example is serving breakfast at a shelter for homeless youth. Medical educators increasingly use service to teach about social determinants of health, to improve attitudes toward underserved populations, and to meet community needs. ${ }^{6-13}$ We aim to measure these abstract yet important positive qualities by selection into Alpha Omega Alpha honor society (AOA) and the Gold Humanism Honor Society (GHHS), which take service as well as academic performance and clinical evaluations into account before admission.

We anticipate that high levels of involvement in service are associated with a residency selection in a primary care field and that service is not detrimental to academic performance, as is reported by other researchers. ${ }^{14,15}$ We expect that service is associated with other positive aspects of being a physician, as measured by selection into AOA and the GHHS. Service participation and residency selection data from students at the UWSOM are used to explore the association between participation in service and primary care career selection. The data collected included years to graduation to evaluate if service award winners had more time to do community service and be biased toward an award, selection into AOA and Gold Humanism to measure excellence in clinical acumen, and percentage matching into primary care. Step 1 and Step 2 scores were also included. They are designed to measure clinical knowledge as part of the United States Medical Licensing Exams and needed for application to residency programs.

Specifically, we ask the questions: are service award winners more likely to enter primary care residencies? Is there a difference in time to graduation between service award recipients versus (vs) non-recipients? Is there an association between service and induction into the GHHS? Does participation in service compromise academic performance? Is service associated with matching into the WWAMI region?

\section{Methods}

The fields we delineate to be primary care are family practice, pediatrics, general internal medicine, and medicinepediatrics, as they are determined to best prepare physicians to practice primary care medicine. ${ }^{16}$ We used three cohort years, graduating years of 2012 (216 students), 2013 (224), and 2014 (226), for 666 students overall, to determine associations between service in medical school and entry into primary care.

We first identified students who demonstrated substantial commitment to service by delineating two groups - one that received the service award and one that did not. The top $15 \%$ of students in each class receive the award. Students are nominated by their peers or they may self-nominate. They are then sent a survey to detail their service activities, service leadership activities, and hours of participation. A selection committee consisting of faculty and staff members receives all completed applications. Service is evaluated for continuity, sustainability, depth and quality of community partnerships, leadership involvement, and demonstrated commitment to building health equity. The committee then sees how many can be awarded based on the $15 \%$ for each class. At the margins of the top $15 \%$ for hours the committee uses the criteria to decide which students receive and do not receive the award.

For AOA election, the top academic quartile is chosen, and the school may elect up to one sixth of the projected number of students who will graduate. Members of AOA in the faculty and current AOA students meet in private to select students for membership. Those students chosen from the top quartile for election are picked not only for their high academic standing, but also for leadership among their peers, professionalism and a firm sense of ethics, promise of future success in medicine, and a commitment to service in the school and community.

The selection for GHHS (http://www.humanism-inmedicine.org/index.php) is two-fold: first by peer-nomination (via survey sent to the entire class), then from the results, a smaller subset is chosen by the current GHHS class and invited to go through a second-round application process, which includes a written essay. The current GHHS class then selects the new members. Of the graduating class, 10\%-15\% is inducted. GHHS recognizes students for "demonstrated excellence in clinical care, leadership, compassion and dedication to service".

This was a retrospective cohort analysis study. The statistical analysis used was "test of proportions". Analyses were conducted using the Statistical Package for the Social Sciences (SPSS Version 18; SPSS Inc., Chicago, IL, USA). The data included years to graduation, selection into AOA and GHHS, Step 1 and Step 2 scores, and percentage matching into primary care. Test of proportions was applied to the two groups of award recipients vs non-recipients with regards to these categories. 
AOA, GHHS and match data are in the public domain. Performance on Step 1 and Step 2 was extracted from a secure data warehouse maintained in the department of biomedical informatics and medical education. Unique identification numbers were allowed in a matching process that blinded investigators to individual identities. Demographic information was not collected from the students including socioeconomic status, and thus no subgroup analysis was performed.

This study did not need ethical review (institutional review board exempt) as an internal evaluation study in the department of bioinformatics.

\section{Results}

There was no correlation between receiving the service award and entering a primary care residency $(57.3 \%$ vs $52.8 \%$, $z$ statistic $0.846, P=0.397$ ), which was the primary outcome being evaluated. There is no difference in time to graduation between the two groups. There is an association between service and induction into GHHS, as well as AOA. There is a significant difference in the proportion of students elected into AOA ( $23.3 \%$ vs $14.6 \%, z$ statistic $2.206, P=0.0274)$. There is a significant difference $(22.6 \%$ vs $10.4 \%, z$ statistic 5.926 , $P<0.001)$ in percentage of students inducted into the GHHS, the award winners being more represented (Table 1).

There is no statistically significant difference between Step 1 scores, or Step 2 scores in the two groups of award recipients/non-recipients (Table 1). There is no trend toward

Table I Characteristics of service award recipients versus nonrecipients

\begin{tabular}{|c|c|c|}
\hline & GI2-14 & GI2-14 \\
\hline & $\begin{array}{l}\text { Received } \\
\text { service award }\end{array}$ & $\begin{array}{l}\text { Did not receive } \\
\text { service award }\end{array}$ \\
\hline $\mathrm{N}$ & 103 & 563 \\
\hline Years to graduation & 4.4 & 4.6 \\
\hline AOA (Alpha Omega Alpha & $23.3 \%$ & $14.6 \%$ \\
\hline \multicolumn{3}{|l|}{ Honor Society)* } \\
\hline GHHS (Gold Humanism & $22.6 \%$ & $10.4 \%$ \\
\hline \multicolumn{3}{|l|}{ Honor Society) ${ }^{\#}$} \\
\hline Step I mean & 226 & 222 \\
\hline Step 2 mean & 242 & 237 \\
\hline Primary care percent & $57.3 \%$ & $52.8 \%$ \\
\hline Family medicine percent & $15.9 \%$ & $17.3 \%$ \\
\hline Match in WWAMI & $33 \%$ & $34.1 \%$ \\
\hline \multicolumn{3}{|l|}{ (Washington, Wyoming, } \\
\hline Alaska, Montana, Idaho region) & & \\
\hline
\end{tabular}

Notes: There is no significant difference in the proportion of students going into primary care ( $z$ statistic $0.846, P=0.397$ ). *There is a significant difference in the proportion of students elected into AOA ( $z$ statistic 2.206, $P=0.0274$ ). ${ }^{\# T h e r e ~ i s ~ a ~}$ significant difference in the proportion of students inducted into GHHS (z statistic 5.926, $P<0.001$ ). GI2-I4: Group 20I2-20I4. matching into primary care and toward matching in the WWAMI region when comparing the service award/no award groups.

\section{Discussion}

While we did not find that students who received the service award were more likely to enter primary care residencies (Table 1), there is a trend in that direction, and one could speculate that our study may reveal patterns if we follow more graduating classes in the future, thus increasing the power. Since we included all graduating students from 2014-2016 no formal power analysis was performed. We worried that students who had more time to spend volunteering (as measured by years to graduation) may confound the data, but that was not the case between the award recipients vs non-recipients. Our data are consistent with the work of others in that it shows that participation in service does not compromise academic achievement, ${ }^{14,15,17}$ as we found no difference between Step 1 and Step 2 scores, between those who received the award and those who did not. A primary barrier to service activity is lack of free time due to academic workload. ${ }^{18}$ This suggests service integrated into the curriculum has a higher chance for successfully impacting students without having deleterious effects on academic performance, as well as strengthening ties with the communities that are served. Perhaps more time allotted for service would allow for stronger associations between service and primary care, something that should be further studied.

The link between selection into AOA and service award winners, as well as GHHS and service award winners, is an encouraging sign for proponents of community service. It suggests a link between aspects of service and high achievement as a medical student and ideally, as physician. We believe induction into AOA and GHHS measures clinical acumen, leadership, and compassion in a more detailed manner than the service award, and in doing so reflects the award winners being more skilled in those areas than their other classmates. Given the findings in this study and the fact that GHHS and AOA are coveted awards that can be a valuable part of a competitive residency application, service can be promoted among medical students as a component of building skills and demonstrating positive values to mentors and residencies. This may or may not promote primary care, but definitely presents an opportunity for positive impact within the community.

There are limitations of this study that need to be considered. These data are from a single institution, and there is a short window from which data were collected. 
Furthermore, some students eligible for the award were in their clinical years with rotations throughout the WWAMI region. These experiences are diverse culturally, geographically, and in the opportunities students have in a given locale to engage in service related activities. We may see different patterns or stronger correlations if greater duration of preclinical service and a larger sample size are included in the calculation, by following further graduating cohorts. We also do not know about further specialization that students may choose to participate in after entry into their residency. At best this study can only measure interest in primary care at the graduation.

Our study unsuccessfully attempted to find a significant link between service and a primary care career choice. It supports previous evidence that service does not compromise academic performance. Further efforts spent in exploring service learning and developing metrics for measuring service may lead to more convincing data and trends, and bolster the theoretical impacts with more tangible results.

\section{Disclosure}

The authors have no conflicts of interest to disclose.

\section{References}

1. Sheldon GF, Ricketts TC, Charles A, King J, Fraher EP, Meyer A. The global health workforce shortage: role of surgeons and other providers. Adv Surg. 2008;42:63-85.

2. Petterson SM, Liaw WR, Phillips RL Jr, Rabin DL, Meyers DS, Bazemore AW. Projecting us primary care physician workforce needs: 2010-2025. Ann Fam Med. 2012;10(6):503-509.

3. Lakhan SE, Laird C. Addressing the primary care physician shortage in an evolving medical workforce. Int Arch Med. 2009;2(1):14.

4. Owen JA, Hayden GF, Connors AF Jr. Can medical school admission committee members predict which applicants will choose primary care careers? Acad Med. 2002;77(4):344-349.

5. Association of American Medical Colleges. AAMC Physician Workforce Policy Recommendations. AAMC, 2012. Available from: https://www. aamc.org/download/304026/data/2012aamcworkforcepolicyrecommen dations.pdf. Accessed January 6, 2015.
6. Community Campus Partnerships for Health. Health Professions Schools in Service to the Nation: Final Evaluation Report. San Francisco: Community Campus Partnerships for Health; 1998. Available from: http://ccph.memberclicks.net/assets/Documents/FocusAreas/ hpsisn\%20final\%20evaluation\%20report\%201996-1998.pdf. Accessed January 6, 2015.

7. Leung AY, Chan SS, Kwan CW, Cheung MK, Leung SS, Fong DY. Service learning in medical and nursing training: a randomized controlled trial. Adv Health Sci Educ Theory Pract. 2012;17(4):529-545.

8. Meah YS, Smith EL, Thomas DC. Student-run health clinic: novel arena to educate medical students on systems-based practice. Mt Sinai J Med. 2009;76(4):344-356.

9. Hunt JB, Bonham C, Jones L. Understanding the goals of service learning and community-based medical education: a systematic review. Acad Med. 2011;86(2):246-251.

10. Berman R, Powe C, Carnevale J, et al. The crimson care collaborative: a student-faculty initiative to increase medical students' early exposure to primary care. Acad Med. 2012;87(5):651-655.

11. Howe A. Patient-centred medicine through student-centred teaching: a student perspective on the key impacts of community-based learning in undergraduate medical education. Med Educ. 2001;35(7):666-672.

12. Klevens J, Valderrama C, Restrepo O, Vargas P, Casasbuenas M, Avella MM. Teaching community oriented primary care in a traditional medical school: a two year progress report. J Community Health. 1992;17(4):231-245.

13. Smith KL, Meah Y, Reininger B, Farr M, Zeidman J, Thomas DC. Integrating service learning into the curriculum: lessons from the field. Med Teach. 2013;35(5):e1139-e1148.

14. Blue AV, Geesey ME, Sheridan ME, Basco WT Jr. Performance outcomes associated with medical school community service. Acad Med. 2006;81(10 Suppl):S79-S82.

15. Brush DR, Markert RJ, Lazarus CJ. The relationship between service learning and medical student academic and professional outcomes. Teach Learn Med. 2006;18(1):9-13.

16. Rivo ML, Saultz JW, Wartman SA, DeWitt TG. Defining the generalist physician's training. JAMA. 1994;271(19):1499-1504.

17. Stoddard HA, Risma JM. Relationship of participation in an optional student-run clinic to medical school grades. Teach Learn Med. 2011;23(1):42-45.

18. Levin MB, Rutkow L. Infrastructure for teaching and learning in the community: the Johns Hopkins University student outreach resource center (source). J Public Health Manag Pract. 2011;17(4):328-336.
Advances in Medical Education and Practice

\section{Publish your work in this journal}

Advances in Medical Education and Practice is an international, peerreviewed, open access journal that aims to present and publish research on Medical Education covering medical, dental, nursing and allied health care professional education. The journal covers undergraduate education, postgraduate training and continuing medical education

\section{Dovepress}

including emerging trends and innovative models linking education, research, and health care services. The manuscript management system is completely online and includes a very quick and fair peer-review system. Visit http://www.dovepress.com/testimonials.php to read real quotes from published authors. 